\title{
The promise of mesenchymal stem cells for intervertebral disc repair
}

\begin{abstract}
The Intervertebral disc (IVD) is a major weight bearing structure which undergoes degenerative changes with ageing limiting its ability to dissipate axial spinal loading in an efficient manner resulting in the generation of low back pain (LBP). LBP is a number one global musculoskeletal disorder with massive socioeconomic impact. The WHO has nominated development of mesenchymal stem cells (MSCs) and bioscaffolds to promote IVD repair as primary research objectives. There is a clear imperative for the development of strategies for the treatment of IVD degeneration and LBP. Early pre-clinical and animal model studies, and preliminary phase I and II clinical trials with MSCs have yielded impressive results in IVD repair. Combinatorial therapeutic approaches encompassing biomaterial and cell-based therapies promise significant breakthroughs in IVD repair in the near future.
\end{abstract}

Keywords: mesenchymal stem cells, intervertebral disc repair, low back pain, cellular proliferation, matrix production
Volume 2 Issue 2 - 2017

\author{
James Melrose ${ }^{1,2,3}$ \\ 'Raymond Purves Bone and Joint Research Laboratory,Australia \\ ${ }^{2}$ Sydney Medical School, Australia \\ ${ }^{3}$ University of New South Wales, Australia
}

Correspondence: James Melrose, Raymond Purves Bone and Joint Research Laboratories, Institute of Bone and Joint Research, Kolling Institute of Medical Research, Level I0, Kolling Building B6, University of Sydney at Royal North Shore Hospital, St. Leonards, NSW 2065, Australia, Tel +6I 2 99264806, Fax +6I 2 99265266,Email james.melrose@sydney.edu.au

Received: February 15, 2017 | Published: February 28, 2017
Abbreviations: DD, disc degeneration; LBP, low back pain; MMP, matrix metallo protease; TIMP, tissue inhibitor of metallo protease; IVD, inter vertebral disc; NP, nucleus pulposus; WHO, world health organization; DALYs, disability adjusted life years; MSCs, mesenchymal stem cells

\section{Introduction}

Disc degeneration (DD) is a major musculoskeletal condition affecting $80 \%$ of the general global population. ${ }^{1}$ The associated low back pain (LBP) has major socioeconomic impact reviewed in. ${ }^{2}$ In the past 25 years a number of promising biological therapies have been investigated for the treatment of degenerative Disc Disease (DDD) and these have identified many potential molecular targets for biologic intervention. ${ }^{3-5}$ These include agents which induce cellular proliferation, matrix production, regulate matrix metallo protease (MMP) and tissue inhibitor of metallo protease (TIMP) production, inflammation, vascular in-growth and cell viability. ${ }^{6}$ The cell density in the IVD is low ${ }^{7}$ and disc cells are exposed to a hostile environment of low oxygen tension, high lactic acid levels, low nutrition and a high hydrostatic pressure leading to cell death and a diminution in cell numbers over time due to cellular senescence, ${ }^{8,9}$ apoptosis ${ }^{10,11}$ and autophagy. ${ }^{12,13}$ The resultant decline in cell number with DD places severe demands on any therapeutic measures to alleviate this condition.

Matricryptins have found application as therapeutic agents in inter vertebral disc (IVD) repair. Hyaluronan oligosaccharides (10-12 mer, HA oligos) stimulate anabolic gene expression, up-regulate MMP2 and 9 synthesis and activation in-vitro. MMP-1, 13, ADAMTS1, ACAN, COL1A1 and COL2A1 gene expression are also up-regulated by HA oligos and annular repair promoted in an annular lesion experimental model of DD. ${ }^{14}$ A small link protein derived peptide (DHLSDNYTLDHDRAIH), link N has cell proliferative properties and the ability to promote and direct matrix synthesis by the resident disc cells. ${ }^{15-18}$ Link $\mathrm{N}$ also promotes Mesenchymal stem cell (MSC) proliferation and differentiation and stimulates IVD repair. ${ }^{19,20}$ Peniel
2000, an en-silico developed biglycan peptide with TGF- $\beta 1$ inhibitory activity has also been used to treat disc degeneration. ${ }^{21}$

Several natural compounds have displayed potential as therapeutic agents in IVD repair. Resveratrol (3, 5, 4'-trihydroxy-trans-stilbene), a plant phenolic compound found in the skins of grapes, blueberries and raspberries provides beneficial effects in the treatment of DD. ${ }^{5,22,23}$ The lipid lowering medications simvastin, ${ }^{4,24,25}$ ortovastatin, and lovastatin $^{26-28}$ all display protective effects on the IVD which may be of application in therapeutic repair strategies. Naringin, a grapefruit flavonoid and component of the Chinese medicinal herb Rhizoma Drynariae has potent anti-inflammatory and anti-oxidant properties, ${ }^{29}$ enhances nucleus pulposus (NP) cell proliferation and down-regulates the effects of tumour necrosis factor (TNF)- $\beta$ on NP cells in-vitro and elevates BMP-2, aggrecan and type II collagen protein production. ${ }^{30}$ Naringin also upregulates ACAN and SOX6 and decreases MMP3 gene expression suggesting that it might be a useful therapeutic agent in the treatment of disc degeneration. Despite their promise as therapeutic agents for IVD repair these molecules have yet to enter the clinic in single or in combination therapies.

A number of studies have used replacement therapy of other connective tissue cells or pluripotent mesenchymal stem cells (MSCs) to treat IVDD, ${ }^{31-34}$ several reviews have extensively documented this area of repair biology. ${ }^{35-38}$ The mode of action whereby MSCs illicit their therapeutic response in-situ however remains elusive. A recent study examined paracrine effects of MSCs isolated from vertebrae in co-cultures with annulus fibrosus (AF) and NP cells. ${ }^{39}$ MSCs down-regulated the expression of pro-inflammatory cytokine genes in degenerate NP (IL-1 $\alpha$, IL-1 $\beta$, IL-6, and TNF- $\alpha$ ) and AF cells (IL$1 \alpha$ and IL-6). These co-cultures also accumulated more extracellular matrix (ECM) than monocultures. In addition, growth factor mRNA expression was upregulated in MSC co-cultures with disc cells, EGF, IGF-1, OP-1, GDF-7 and TGF- $\beta$ were all up-regulated in NP cell cultures and IGF-1, OP-1 and GDF-7 in AF cells. This therapeutic effect is in keeping with the use of these growth factors to effect biological repair of degenerate IVDs ${ }^{40,41}$ and also establishes a paracrine mode of 
action for MSCs. The Euro DISC clinical trial for the treatment of DD ${ }^{42}$ investigated the transplantation of expanded autologous chondrocytes in patients undergoing single level discectomy. Interim analysis of 28 patients at 24 months showed chondrocyte transplantation produced greater pain reduction and increased IVD fluid content as shown MRI. Percutaneous injection of expanded autologous MSCs in two small non-controlled clinical trials improved MRI T2 signal and clinical improvement. ${ }^{43,44}$ Administration of autologous bone marrow MSCs in two small series of patients with IVDD resulted in clinical improvement in 9 of 10 patients compared to conservative treatment which failed ${ }^{43,44}$ A phase II clinical trial has been conducted with adult bone marrow MSCs for the treatment of back pain. ${ }^{45} \mathrm{~A}$ majority of the MSC treated patients achieved minimal levels of residual back pain and other indices of clinical improvement. A multi centre Phase III clinical trial is currently being conducted on the use of MSCs for the treatment of disc degeneration in 25 centres throughout the USA and the findings of these studies are eagerly awaited.

A recent ten-year global study which surveyed 291 major human diseases placed LBP as the number one musculoskeletal disorder. ${ }^{46}$ Approximately $80 \%$ of the general populations in Western Societies are affected by LBP and its incidence increases with aging, peaking in the fifth and sixth decade. ${ }^{46}$ In 1998 UK costings for the treatment of LBP were costed at $£ 12.3$ billion, ${ }^{47}$ in 2001 LBP cost $\$ 9.17$ billion in Australia. ${ }^{48}$ In 2006 the American Academy of Pain Medicine published costs for chronic pain in the USA at \$560-635billion/ annually, $53 \%$ of all chronic pain patients had LBP and 31million people were estimated to suffer from LBP at any one time. ${ }^{1,6,49}$ In 1999 the World Health Organization (WHO) published the IRIS low back pain initiative ${ }^{50}$ which highlighted LBP as a priority area and designated the development of biomaterials for disc replacement and stem cell methodology to restore functional IVDs as high priority research areas. ${ }^{2}$ LBP was also made a national research priority area by the National Health and Medical Research Council (NHMRC) and Australian Institute of Health and Welfare (AIHW) in $2009^{49}$ but to date have failed to fund any innovative projects designed to alleviate or better understand this condition. This is a major deficiency given the major and ever-increasing impact LBP makes on the Australian community, affects which are mirrored in other global communities. ${ }^{48,51}$ Recent findings of the global burden of disease study 2010 [46] found that of the 289 major human diseases examined, LBP ranked highest in terms of overall disability in terms of disability adjusted life years (DALYs) confirming the impact of LBP on the daily life of all individuals. ${ }^{52-54}$

\section{Conclusion}

Information presented in this mini review shows that there is a clear need for the development of effective measures for the treatment of DD and LBP. MSCs represent one area of considerable potential in this area of repair biology and it is to be hoped that funding agencies understand the true therapeutic potential of MSCs and support such ventures accordingly.

\section{Acknowledgements}

None.

\section{Conflict of interest}

The author declares no conflict of interest.

\section{References}

1. Andersson G. The Epidemiology of Spinal Disorders. In: JW F, editor. The Adult Spine: Principles and Practice. USA: Lippincott-Raven; 1997. p. 93-141.

2. Melrose J. Strategies in regenerative medicine for intervertebral disc repair using mesenchymal stem cells and bioscaffolds. Regen Med. 2016;11(7):705-724.

3. Maidhof R, Alipui DO, Rafiuddin A, et al. Emerging trends in biological therapy for intervertebral disc degeneration. Discov Med. 2012;14(79):401-411.

4. Than KD, Rahman SU, Wang L, et al. Intradiscal injection of simvastatin results in radiologic, histologic, and genetic evidence of disc regeneration in a rat model of degenerative disc disease. Spine J. 2014;14(6):1017-1028.

5. Wuertz K, Quero L, Sekiguchi M, et al. The red wine polyphenol resveratrol shows promising potential for the treatment of nucleus pulposus-mediated pain in vitro and in vivo. Spine (Phila Pa 1976). 2011;36(21):E1373-E1384.

6. Anderson DG, Tannoury C. Molecular pathogenic factors in symptomatic disc degeneration. Spine J. 2005;5(6 Suppl):260S-266S.

7. Maroudas A, Stockwell RA, Nachemson A, et al. Factors involved in the nutrition of the human lumbar intervertebral disc: cellularity and diffusion of glucose in vitro. J Anat. 1975;120(Pt 1):113-130.

8. Vo NV, Hartman RA, Patil PR, et al. Molecular mechanisms of biological aging in intervertebral discs. J Orthop Res. 2016;34(8):1289-1306.

9. Wang F, Cai F, Shi R, et al. Aging and age related stresses: a senescence mechanism of intervertebral disc degeneration. Osteoarthritis Cartilage. 2016;24(3):398-408.

10. Kermani HR, Hoboubati H, Esmaeili Mahani S, et al. Induction of intervertebral disc cell apoptosis and degeneration by chronic unpredictable stress. J Neurosurg Spine. 2014;20(5):578-584.

11. Kuo YJ, Wu LC, Sun JS, et al. Mechanical stress-induced apoptosis of nucleus pulposus cells: an in vitro and in vivo rat model. J Orthop Sci. 2014;19(2):313-322.

12. Gruber HE, Hoelscher GL, Ingram JA, et al. Autophagy in the degenerating human intervertebral disc: in vivo molecular and morphological evidence, and induction of autophagy in cultured annulus cells exposed to pro inflammatory cytokines-implications for disc degeneration. Spine (Phila Pa 1976). 2015;40(11):773-782.

13. Ma KG, Shao ZW, Yang SH, et al. Autophagy is activated in compression-induced cell degeneration and is mediated by reactive oxygen species in nucleus pulposus cells exposed to compression. Osteoarthritis Cartilage. 2013;21(12):2030-2038.

14. Fuller ES, Shu C, Smith MM, et al. Hyaluronan Oligosaccharides Stimulate MMP and Anabolic Gene Expression in-vitro by Intervertebral Disc Cells and Annular Repair in-vivo. J Tissue Eng Regen Med. 2016;12(1):e216-e226.

15. Gawri R, Antoniou J, Ouellet J, et al. Best paper NASS 2013: link-N can stimulate proteoglycan synthesis in the degenerated human intervertebral discs. Eur Cell Mater. 2013;26:107-119.

16. Mwale F, Demers CN, Petit A, et al. A synthetic peptide of link protein stimulates the biosynthesis of collagens II, IX and proteoglycan by cells of the intervertebral disc. $J$ Cell Biochem. 2003;88(6):1202-1213.

17. Mwale F, Masuda K, Pichika R, et al. The efficacy of Link N as a mediator of repair in a rabbit model of intervertebral disc degeneration. Arthritis Res Ther. 2011;13(4):R120. 
18. Petit A, Yao G, Rowas SA, et al. Effect of synthetic link N peptide on the expression of type I and type II collagens in human intervertebral disc cells. Tissue Eng Part A. 2011;17(7, 8):899-904.

19. Antoniou J, Wang HT, Alaseem AM, et al. The effect of Link N on differentiation of human bone marrow-derived mesenchymal stem cells. Arthritis Res Ther. 2012;14(6):R267.

20. Mwale F, Wang HT, Roughley P, et al. Link N and Mesenchymal Stem Cells Can Induce Regeneration of the Early Degenerate Intervertebral Disc. Tissue Eng Part A. 2014;20(21,22):2942-2949.

21. Kwon YJ, Lee JW, Moon EJ, et al. Anabolic effects of Peniel 2000, a peptide that regulates TGF-betal signaling on intervertebral disc degeneration. Spine (Phila Pa 1976). 2013;38(2):E49-58.

22. Kwon YJ. Resveratrol has anabolic effects on disc degeneration in a rabbit model. J Korean Med Sci. 2013;28(6):939-945.

23. Li X, Phillips FM, An HS, et al. The action of resveratrol, a phytoestrogen found in grapes, on the intervertebral disc. Spine (Phila Pa 1976). 2008;33(24):2586-2595.

24. Zhang H, Lin CY. Simvastatin stimulates chondrogenic phenotype of intervertebral disc cells partially through BMP-2 pathway. Spine (Phila Pa 1976). 2008;33(16):E525-E531.

25. Zhang H, Wang L, Park JB, et al. Intradiscal injection of simvastatin retards progression of intervertebral disc degeneration induced by stab injury. Arthritis Res Ther. 2009;11(6):R172.

26. Gologorsky Y, Chi J. Statins for disc degeneration. Neurosurgery. 2014;74(4):N18-N19.

27. $\mathrm{Hu} \mathrm{MH}$, Yang $\mathrm{KC}$, Chen $\mathrm{YJ}$, et al. Lovastatin prevents discographyassociated degeneration and maintains the functional morphology of intervertebral discs. Spine J. 2014;14(10):2459-2466.

28. Karamouzian S, Eskandary H, Saeed A, et al. Effect of atorvastatin on angiogenesis in degenerated intervertebral disc in rat. Spine (Phila Pa 1976). 2011;36(22):1824-1828.

29. Alam MA, Subhan N, Rahman MM, et al. Effect of citrus flavonoids, naringin and naringenin, on metabolic syndrome and their mechanisms of action. Adv Nutr. 2014;5(4):404-417.

30. Li N, Whitaker $\mathrm{C}, \mathrm{Xu} \mathrm{Z}$, et al. Therapeutic effects of naringin on degenerative human nucleus pulposus cells for discogenic low back pain Spine J. 2016;16(10):1231-1237.

31. Freeman BJ, Kuliwaba JS, Jones CF, et al. Allogeneic mesenchymal precursor cells promote healing in postero-lateral annular lesions and improve indices of lumbar intervertebral disc degeneration in an ovine model. Spine (Phila Pa 1976). 2016;41(17):1331-1339.

32. Pettine K, Suzuki R, Sand T, et al. Treatment of discogenic back pain with autologous bone marrow concentrate injection with minimum two year follow-up. Int Orthop. 2016;40(1):135-140.

33. Sakai D, Andersson GB. Stem cell therapy for intervertebral disc regeneration: obstacles and solutions. Nat Rev Rheumatol. 2015;11(4):243256.

34. Zeckser J, Wolff M, Tucker J, et al. Multipotent Mesenchymal Stem Cell Treatment for Discogenic Low Back Pain and Disc Degeneration. Stem Cells Int. 2016;2016:13.

35. Longo UG, Papapietro N, Petrillo S, et al. Mesenchymal stem cell for prevention and management of intervertebral disc degeneration. Stem Cells Int. 2012;2012:921053.

36. Oehme D, Goldschlager T, Ghosh P, et al. Cell-based therapies used to treat lumbar degenerative disc disease: a systematic review of animal studies and human clinical trials. Stem Cells Int. 2015;2015:946031.
37. Oehme D, Goldschlager T, Rosenfeld JV, et al. The role of stem cell therapies in degenerative lumbar spine disease: a review. Neurosurg Rev. 2015;38(3):429-445.

38. Richardson SM, Hoyland JA, Mobasheri R, et al. Mesenchymal stem cells in regenerative medicine:opportunities and challenges for articular cartilage and intervertebral disc tissue engineering. J Cell Physiol. 2010;222(1):23-32

39. Shim EK, Lee JS, Kim DE, et al. Autogenous mesenchymal stem cells from the vertebral body enhance intervertebral disc regeneration by paracrine interaction: an in vitro pilot study. Cell Transplant. 2016;25(10):1819-1832.

40. An HS, Thonar EJ, Masuda K. Biological repair of intervertebral disc. Spine(Phila Pa 1976). 2003;28(Suppl 15):S86-S92.

41. Masuda K. Biological repair of the degenerated intervertebral disc by the injection of growth factors. Eur Spine J. 2008;17 (Suppl 4):441-451.

42. Meisel HJ, Siodla V, Ganey T, et al. Clinical experience in cell-based therapeutics:disc chondrocyte transplantation A treatment for degenerated or damaged intervertebral disc. Biomol Eng. 2007;24(1):5-21.

43. Orozco L, Soler R, Morera C, et al. Intervertebral disc repair by autologous mesenchymal bone marrow cells: a pilot study. Transplantation. 2011;92(7):822-828.

44. Yoshikawa T, Ueda Y, Miyazaki K, et al. Disc regeneration therapy using marrow mesenchymal cell transplantation: a report of two case studies. Spine(Phila Pa 1976). 2010;35(11):E475-E480.

45. Bae H, Amirdelfan K, Coric D, et al. A phase II study demonstrating efficacy and safety of mesenchymal precursor cells in low back pain due to disc degeneration. Spine J. 2014;14(11):S31-S32.

46. Vos T, Flaxman AD, Naghavi M, et al. Years lived with disability (YLDs) for 1160 sequelae of 289 diseases and injuries 1990-2010: a systematic analysis for the Global Burden of Disease Study 2010. Lancet. 2012;380(9859):2163-2196.

47. Maniadakis N, Gray A. The economic burden of back pain in the UK. Pain. 2000;84(1):95-103.

48. Walker BF, Muller R, Grant WD. Grant, Low back pain in Australian adults:the economic burden. Asia Pac J Public Health. 2003;15(2):7987.

49. Briggs AM, Buchbinder R. Back pain: a National Health Priority Area in Australia? Med J Aust. 2009;190(9):499-502.

50. Ehrlich G, Khaltaev NG. Low Back Pain Initiative. In: EEGKN Team, editors. Chronic Respiratory Diseases and Arthritis. Switzerland: World Health Organisation; 1999. 152 p.

51. Walker BF, Muller R, Grant WD. Grant, Low back pain in Australian adults: prevalence and associated disability. J Manipulative Physiol Ther. 2004;27(4):238-244.

52. Hoy D, March L, Brooks P, et al. The global burden of low back pain: estimates from the Global Burden of Disease 2010 study. Ann Rheum Dis. 2014;73(6):968-974.

53. Hoy D, March L, Brooks P, et al. Measuring the global burden of low back pain. Best Pract Res Clin Rheumatol. 2010;24(2):155-165.

54. Hoy DG, Smith E, Cross M, et al. The global burden of musculoskeletal conditions for 2010: an overview of methods. Ann Rheum Dis. 2014;73(6):982-989. 